\title{
Evaluation of response to restraint stress by salivary corticosterone levels in adult male mice
}

\author{
Masakatsu NOHARA ${ }^{1)}$, Atsushi TOHEI ${ }^{1) *}$, Takumi SATO ${ }^{1)}$ and Hiromi AMAO ${ }^{1)}$ \\ ${ }^{1)}$ Laboratory of Experimental Animal Science, Nippon Veterinary and Life Science University, 1-7-1 Kyonan-cho, Musashino, Tokyo \\ 180-8602, Japan
}

(Received 27 October 2015/Accepted 8 January 2016/Published online in J-STAGE 8 February 2016)

ABSTRACT. Saliva as a sampling method is a low invasive technique for the detection of physiologically active substances, as opposed to sampling the plasma or serum. In this study, we obtained glucocorticoids transferred from the blood to the saliva from mice treated with $2.0 \mathrm{mg} / \mathrm{kg}$ via an intraperitoneal injection of cortisol. Next, to evaluate the effect of restraint stress using mouse saliva—collected under anesthesia by mixed anesthetic agents - we measured plasma and salivary corticosterone levels at 60 min after restraint stress. Moreover, to evaluate salivary corticosterone response to stress in the same individual mouse, an adequate recovery period (1, 3 and 7 days) after anesthesia was examined. The results demonstrate that exogenous cortisol was detected in the saliva and the plasma, in mice treated with cortisol. Restraint stress significantly increased corticosterone levels in both the plasma and saliva $(P<0.001)$. Monitoring the results of individual mice showed that restraint stress significantly increased salivary corticosterone levels in all three groups (1-, 3- and 7-day recovery). However, the statistical evidence of corticosterone increase is stronger in the 7 -day recovery group $(P<0.001)$ than in the others $(P<0.05)$. These results suggest that the corticosterone levels in saliva reflect its levels in the plasma, and salivary corticosterone is a useful, less-invasive biomarker of physical stress in mice. The present study may contribute to concepts of Reduction and Refinement of the three Rs in small animal experiments.

KEY WORDS: less invasive, mixed anesthetic agents, restraint stress, saliva, the three Rs

doi: 10.1292/jvms.15-0610; J. Vet. Med. Sci. 78(5): 775-780, 2016

\section{INTRODUCTION}

Plasma and serum samples are generally acceptable for the detection of various physiologically active substances; however, drawing blood can induce stress in animals. In the instance of collecting repeated blood samples from mice, using the saphenous and lateral tail vein are recommended. These sites yield a $5 \%$ volume of circulating blood from the saphenous veins and $0.1-0.15 \mathrm{~m} l$ from lateral tail vein [5]. However, the small volume of blood sampled limits detection of substances by any assay. Blood sampling by decapitation or cardiac puncture is employed as a collection method to obtain whole blood, gathering approximately $1 \mathrm{~m} l$ of whole blood and $0.5 \mathrm{~m} l$ of plasma. This volume is adequate to measure multiple substances using an immunoassay. In this case, a large number of mice are required, due to the sacrifice of animals at each time point when exhibiting responses to experimental treatments. In addition to this problem, it is impossible to investigate multiple time points, before and after responses to the treatment in the same mouse. Alternatively, non-invasive samples (including feces, urine and saliva) can be used for the assays. In particular, many studies discuss

\footnotetext{
${ }^{*}$ Correspondence to: Tohei, A., Laboratory of Experimental Animal Science, Nippon Veterinary and Life Science University, 1-7-1 Kyonan-cho, Musashino, Tokyo 180-8602, Japan.

e-mail: tohei@nvlu.ac.jp

(C)2016 The Japanese Society of Veterinary Science

This is an open-access article distributed under the terms of the Creative Commons Attribution Non-Commercial No Derivatives (by-nc-nd) License $<$ http://creativecommons.org/licenses/by-nc-nd/4.0/>.
}

salivary biomarkers in responses to stress (for reviews $[10,21])$. Stress responsive biomarkers, including glucocorticoid, $\alpha$-amylase and chromogranin A, have demonstrated some correlations between salivary and plasma concentration in human and animals $[19,21]$. However, there are few reports evaluating saliva for these biomarkers in response to stress using small experimental animals, particularly mice.

Human saliva can be easily collected using absorbent materials, such as cotton balls, placed in the mouth. In contrast, it is more difficult to obtain mouse saliva as mice swallow their saliva while they are awake; thus, the mice need an anesthetic for saliva collection $[3,11]$. In addition to anesthesia, pilocarpine (muscarinic receptor agonist) is also needed as a salivator $[11,30]$, since salivary volume is expected to be low without pilocarpine. However, anesthesia itself may induce a stress response $[1,4]$ in mice during saliva collection.

In order to clarify whether the salivary corticosterone is available to evaluate stress response in mice, first we confirmed the transfer of glucocorticoid from the blood to the saliva after administration of exogenous cortisol. Secondly, we compared corticosterone levels between plasma and saliva in response to restraint stress, and finally, we investigated the adequate recovery, at set intervals after anesthesia, for saliva collection between pre-stress and post-stress in mice.

\section{MATERIALS AND METHODS}

Animals: Adult male ICR mice were purchased from Kiwa Laboratory Animals Co., Ltd. (Wakayama, Japan) and used throughout the present study. All mice were allowed ad libitum access to a commercial diet (EF; Oriental Yeast Co., 
Ltd., Tokyo, Japan) and tap water. Mice were maintained under controlled conditions: temperature $\left(23-25^{\circ} \mathrm{C}\right)$, relative humidity (40-60\%) and light (12 hr, 07:00-19:00 hr). Nineto thirteen-week-old animals were used in each experiment; their body weights before the experiment were $42.0 \pm 0.3 \mathrm{~g}$ (mean \pm standard error). Mice were treated according to the provisions for animal welfare of the Nippon Veterinary and Life Science University, which follows the Guidelines for Animal Experimentation issued by the Japanese Association for Laboratory Animal Science [12].

Drug preparation: All agents were injected intraperitoneally (IP) at an injection volume of $0.1 \mathrm{ml} / 10 \mathrm{~g}$ body weight/ mouse. A mixture of three drugs (medetomidine, midazolam and butorphanol) acting as the anesthetic agents, were used throughout the present study. The injection of atipamezole (an antagonist of medetomidine) allowed mice to undergo a rapid recovery from anesthesia $[6,25]$. The mixed anesthetic agents were prepared as a three-drug mix [15], modifying the dose slightly dose according to Naganuma et al. [20]. The preparation involved using sterilized saline $(0.9 \%)$ : $0.3 \mathrm{mg} / \mathrm{kg}$ of medetomidine hydrochloride (Domitor ${ }^{\circledR}$; Nippon Zenyaku Kogyo Co., Ltd., Fukushima, Japan), 6.0 mg/ kg of midazolam (Dormicum ${ }^{\circledR}$; Astellas Pharma Inc., Tokyo, Japan) and $7.5 \mathrm{mg} / \mathrm{kg}$ of butorphanol tartrate (Vetorphale ${ }^{\circledR}$; Meiji Seika Pharma Co., Ltd., Tokyo, Japan). Pilocarpine hydrochloride (Nacalai Tesque, Inc., Kyoto, Japan), as a salivator to enhance salivary secretion, and atipamezole hydrochloride (Antisedan ${ }^{\circledR}$; Nippon Zenyaku Kogyo Co., Ltd.), as an antagonist of medetomidine, were dissolved in saline and treated at a dosage of 0.5 and $0.3 \mathrm{mg} / \mathrm{kg}$, respectively. Cortisol (hydrocortisone; Nacalai Tesque, Inc.) was dissolved in sesame oil (Nacalai Tesque, Inc.) and treated at a dosage of $2.0 \mathrm{mg} / \mathrm{kg}$. Cortisol is the glucocorticoid produced principally in humans but not in rodents.

Saliva collection procedure: Mice were treated with the mixed anesthetic agents, and 10 min later, they were additionally treated with pilocarpine $(0.5 \mathrm{mg} / \mathrm{kg} \mathrm{IP})$. Saliva was collected for $40 \mathrm{~min}$ by absorption onto a cotton roll (of approximately $5 \mathrm{~mm}$ in diameter, $10 \mathrm{~mm}$ in length) and placed in the oral cavity, exchanging the cotton occasionally. After the end of the saliva collection, atipamezole was injected into mice to allow recovery from the anesthetic. During anesthesia and saliva collection, the body temperature of the mice was maintained at $38^{\circ} \mathrm{C}$ by using a heating plate. To extract saliva from the cotton rolls, they were transferred to $1.5 \mathrm{~m} l$ centrifuge tube with a hole (approximately $1.5 \mathrm{~mm}$ in diameter) at the bottom onto empty the tube. The tubes were centrifuged at $3,000 \times \mathrm{g}$ for $30 \mathrm{~min}$.

Effect of cortisol administration on cortisol levels in plasma and saliva: Mice were treated simultaneously with the mixed anesthetic agents and $2.0 \mathrm{mg} / \mathrm{kg}$ IP of cortisol or by vehicle injection, and $10 \mathrm{~min}$ later, they were additionally treated with pilocarpine. After the end of the saliva collection, mice were euthanized by decapitation under anesthesia, and trunk blood was collected in heparinized sampling tubes. Blood samples were centrifuged to obtain the plasma for the determination of cortisol levels by enzyme immunoassay (EIA).
Comparison of corticosterone levels before and after the restraint stress in plasma without anesthesia: The restraint stress group was immobilized for $60 \mathrm{~min}$ by a restrainer that was made of transparent acrylic, forming a cylinder (ICN3; inner diameter, $36 \mathrm{~mm}$; length $100 \mathrm{~mm}$; ICM Co., Ltd., Ibaraki, Japan) and euthanized by decapitation immediately after the restraint stress. The intact control group was euthanized by decapitation without restraint treatment. Blood samples were treated as described above, and the plasma was obtained for the determination of corticosterone levels by EIA.

Comparison of corticosterone levels before and after the restraint stress in plasma and saliva under anesthesia: The restraint stress group was immobilized for $60 \mathrm{~min}$ by the restrainer and then treated with the mixed anesthetic agents immediately after release from the restraint. At the end of the 40 min saliva collection period, mice were euthanized by decapitation for blood sample collection. On the other hand, the intact control group without restraint stress was euthanized by decapitation after the saliva collection under anesthesia.

Investigation of the adequate recovery period from anesthesia for saliva collection: To investigate the adequate recovery period from anesthesia for saliva collection between pre-stress and post-stress in the same individual, three different recovery times were examined. For the collection of saliva samples in the pre-stress condition, the male mice without restraint stress were treated with the mixed anesthetic agents, and saliva was collected for 40 min under anesthesia. After 1, 3 and 7 days since the first saliva collection, the same individual male mice were immobilized for 60 min by the restrainer and treated with the mixed anesthetic agents immediately after release from the restraint. Saliva was collected for $40 \mathrm{~min}$, and atipamezole was injected into mice for recovery from anesthesia at the end of the saliva collection.

Enzyme immunoassay and statistical analysis: Plasma samples were extracted by diethyl ether, according to the method described by Kanesaka et al. [14] for the measurement of cortisol or corticosterone levels.

The levels of cortisol and corticosterone in plasma and saliva were measured by competitive enzyme immunoassay, using anti-cortisol-3-CMO-BSA IgG (FKA 404-E; Cosmo Bio Co., Ltd., Tokyo, Japan) and anti-corticosterone3-CMO-BSA IgG (FKA 420-E; Cosmo Bio Co., Ltd.) as the primary antibody. Cortisol-3-CMO-HRP (FKA 403; Cosmo Bio Co., Ltd.) and corticosterone-3-CMO-HRP (FKA 419; Cosmo Bio Co., Ltd.) were used as the labeled steroid. The intra- and inter-assay coefficients of variation were 4.5 and $4.4 \%$ for cortisol, and 7.0 and $14.0 \%$ for corticosterone, respectively. The cross-reactivity of anti-cortisol was $2.0 \%$ with corticosterone.

All results are expressed as the mean \pm standard error $(S E)$. Student's $t$-test or paired $t$-test was performed using JSTAT software, version 10.0 for Windows (http://toukeijstat.web. fc2.com/), for the data analysis of plasma and salivary corticosterone levels. The differences were considered significant at probabilities of less than $5 \%(P<0.05)$. 


\section{RESULTS}

Effect of cortisol administration on cortisol levels in plasma and saliva: The results are shown in Fig. 1. The cortisol levels in the treatment group administered with $2.0 \mathrm{mg} / \mathrm{kg}$ IP of cortisol were $633.1 \pm 35.9 \mathrm{ng} / \mathrm{ml}$ in the plasma and $75.6 \pm$ $4.4 \mathrm{ng} / \mathrm{ml}$ in the saliva. Salivary cortisol was not detected in the group treated by vehicle injection, while plasma cortisol was detected by EIA; however, it was only represented by very low levels. The total salivary cortisol levels, from 10 to $50 \mathrm{~min}$ after the treatment of cortisol, were approximately $12 \%$ of the plasma cortisol levels at the time point of $50 \mathrm{~min}$ after the treatment.

Comparison of corticosterone levels before and after the restraint stress in plasma without anesthesia: Figure 2A indicates the corticosterone levels of plasma obtained immediately after 60 min restraint stress without anesthesia. The levels of the restraint group were significantly higher than the levels of the intact group $(403.0 \pm 16.5$ vs. $97.9 \pm$ $12.1 \mathrm{ng} / \mathrm{ml}, P<0.001)$.

Comparison of corticosterone levels before and after the restraint stress in plasma and saliva under anesthesia: Figure $2 \mathrm{~B}$ indicates the corticosterone levels of plasma and saliva under anesthesia. The plasma was obtained after the end of the 40 min saliva collection following restraint stress. The plasma corticosterone levels of the restraint group were significantly higher than the levels of the intact group (258.5 \pm 11.3 vs. $170.4 \pm 6.0 \mathrm{ng} / \mathrm{ml}, P<0.001)$. The salivary corticosterone levels of the restraint group were also significantly higher than the levels of the intact group $(19.7 \pm 1.8$ vs. 6.3 $\pm 1.3 \mathrm{ng} / \mathrm{ml}, P<0.001)$.

Investigation of the adequate recovery period from anesthesia for saliva collection: The results are shown in Fig. 3. The salivary corticosterone levels of the 1-, 3- and 7-day recovery group (Day 1, Day 3 and Day 7) treated with restraint stress were significantly higher than the levels of the respective intact control. The numerical results were as follows: Day $1,11.3 \pm 0.9$ vs. $8.1 \pm 1.2 \mathrm{ng} / \mathrm{ml}, P=0.0429$; Day $3,11.7$ \pm 1.7 vs. $4.4 \pm 0.8 \mathrm{ng} / \mathrm{ml}, P=0.0165$; and Day $7,14.1 \pm 1.5$ vs. $5.4 \pm 0.5 \mathrm{ng} / \mathrm{ml}, P<0.001$. The ratio of salivary corticosterone levels from the recovery groups with restraint stress was compared with the levels of each intact control group. The 7-day recovery group showed a significant increase in salivary corticosterone levels compared to the intact control group, $P=0.0036$. On the other hand, 1- and 3-day recovery groups did not show a significant increase in levels when compared with each intact control group, $P=0.1247$ and $P=0.0610$ (data not shown as the figure). In addition to this comparison, the increase of salivary corticosterone induced by restraint stress, was significantly suppressed $(P<0.01$; One-way ANOVA followed by Tukey's test) in 1-day or 3-day recovery (repeated anesthesia) group (Fig. 3) compared to anesthesia-naive group (Fig. 2B). The increased corticosterone secretion was not suppressed in the 7-day recovery (repeated anesthesia) group (data not shown).

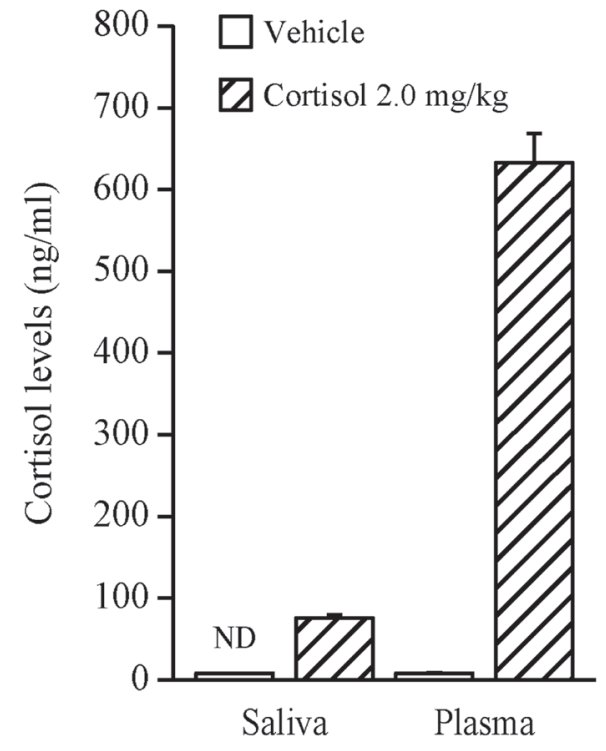

Fig. 1. Effect of cortisol injection $(2.0 \mathrm{mg} / \mathrm{kg} \mathrm{IP})$ on plasma and salivary cortisol levels in adult male ICR mice. Each value represents the mean $\pm S E$ of six animals. ND denotes 'not detectable'.

\section{DISCUSSION}

In this paper, cortisol was detected in both the plasma and saliva as a result of the IP administration of cortisol. On the other hand, cortisol was not detected in the saliva, but was detected in the plasma at very low levels, after treatment with vehicle (Fig. 1). Rodents, including mice, possess corticosterone as a glucocorticoid and do not retain endogenous cortisol. In the present study, the anti-cortisol showing $2 \%$ cross-reactivity with corticosterone was used for EIA. The reason why cortisol was detected in vehicle control group, might be accounted for by the cross-reactivity of anti-cortisol. Cortisol unconjugated with protein in the blood circulation has been reported to pass easily through the acinar cells on the secretory end-piece of the salivary glands [16]. The present data showed that the origin of cortisol-detected in mouse saliva-is exogenous corticosteroid and that the cortisol was considered to spread to the saliva from the blood via the salivary glands, suggesting that glucocorticoids in saliva may reflect the levels present in the blood circulation.

The result of the present study indicated that the restraint stress significantly increased plasma and salivary corticosterone levels (Fig. 2), and our observations agreed with previous studies, reporting plasma corticosterone levels in mice and rats treated with restraint stress [9, 22, 28, 29]. In humans, saliva, in addition to blood samples, is readily available for the measurement of cortisol in various stressrelated studies $[8,13,26]$. However, there is no scientific literature mentioning salivary corticosterone levels in mice treated with stress, with only one study reporting salivary corticosterone in rats treated with isolation stress [2]. The present report indicates that mouse salivary corticosterone is 

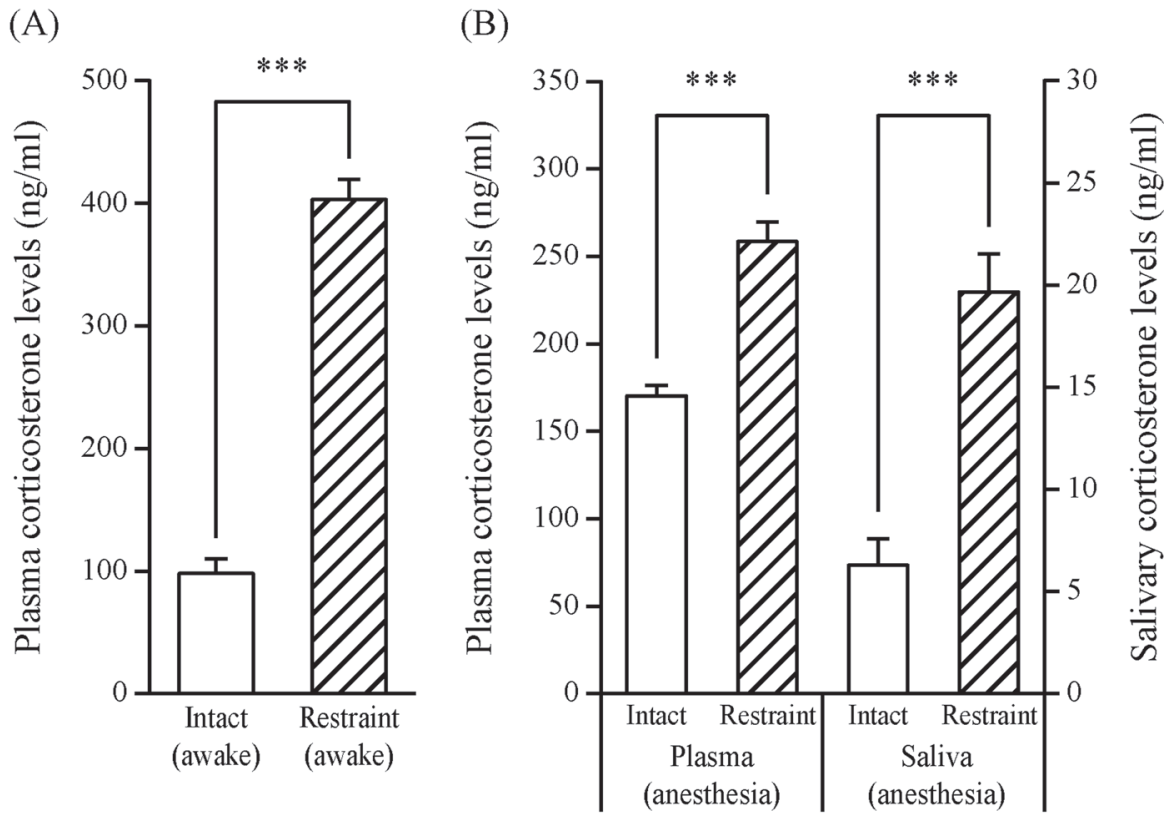

Fig. 2. Effects of restraint stress $(60 \mathrm{~min})$ on corticosterone levels in adult male ICR mice treated with or without anesthesia. The restraint group was euthanized by decapitation immediately after the restraint stress $(60 \mathrm{~min})$ without anesthesia (A). The intact and restraint groups were euthanized by decapitation after saliva collection, and saliva was collected for $40 \mathrm{~min}$ following $10 \mathrm{~min}$ anesthesia induction (B). Each value represents the mean $\pm S E$ of six to seven animals. The open bars show intact control (non-stress) group, and the hatched bars show restraint stress groups. Statistically significant corticosterone levels were determined by Student's $t$-test $(* * * P<0.001)$.

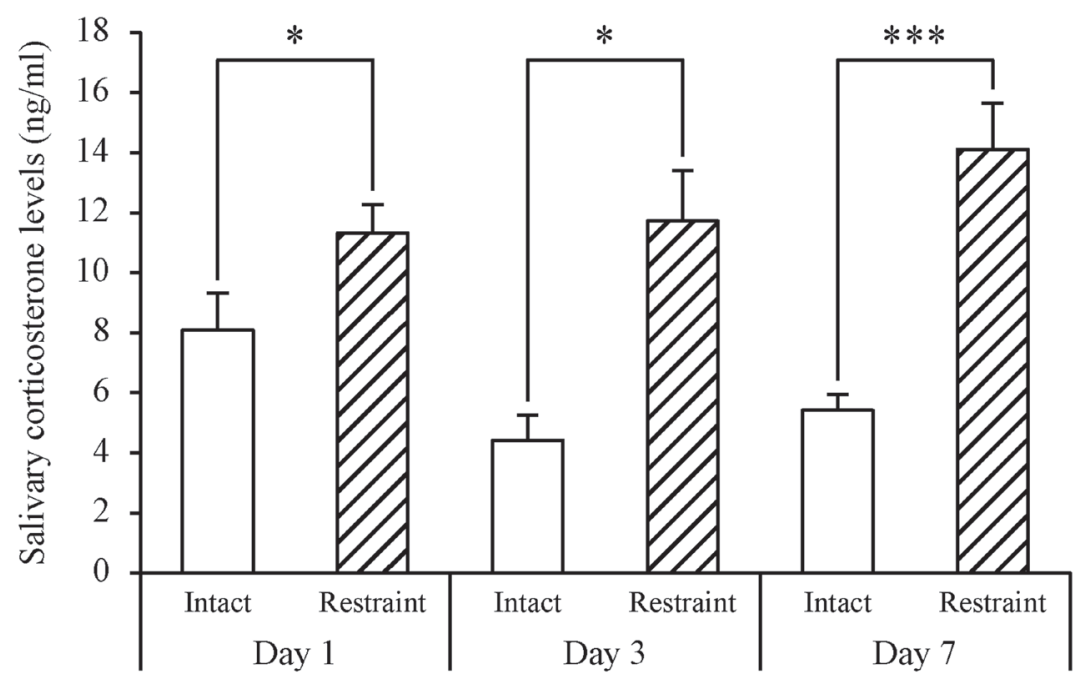

Fig. 3. Examination of adequate recovery period from anesthesia for saliva sampling in stress experiment using adult male ICR mice tested as individuals. On 1, 3 and 7 days (Day 1, Day 3 and Day 7, respectively) after the prior saliva collections (intact control groups), saliva was collected again following restraint stress $(60 \mathrm{~min})$ by the restrainer. Each value represents the mean $\pm S E$ of seven to ten animals. The open bars show intact control groups, and the hatched bars show restraint stress groups. Statistically significant corticosterone levels were determined by Student's paired $t$-test $(* P<0.05$, $* * * P<0.001)$. 
detected and the level is significantly increased following 60 min restraint stress. These results suggest that salivary corticosterone levels reflect changes in plasma corticosterone levels, caused by induced restraint stress in mice.

In the experiments investigating the adequate recovery periods from anesthesia, three different time periods $(1,3$ and 7 days) were set. Restraint stress significantly increased salivary corticosterone levels in all three groups (Fig. 3); even so, the statistical evidence of corticosterone increase is stronger in a 7-day recovery group $(P<0.001)$ than the others $(P<0.05)$. When comparing the ratio of corticosterone levels of intact control group, restraint stress increased the levels significantly in 7-day recovery group, but did not significantly increase the levels in 1- and 3-day recovery groups (data not shown as the figure). Repeated restraint stress after 7 days, increased the levels of plasma corticosterone. In rats, a study shows an increase of heterogeneous nuclear RNA of corticotrophin-releasing hormone in the paraventricular nucleus - equivalent to levels in single acute stress - while the others experiencing repeated restraint stress (daily, alternate days and at 3 day intervals) increased, but to lower equivalent levels of single acute stress [17]. Moreover, rat serum corticosterone levels elevated by repeated nicotine treatment as a chemical stress, decreased to baseline levels after 7 days withdrawal [23]. Nicotine elevated the rat plasma adrenocorticotropic hormone levels [18] in addition to corticosterone, suggesting that this treatment would induce chemical stress in animals. These previous studies also indicate that the recovery period from physical or chemical stress is estimated at one week. Additionally, the previous studies showing that the diethyl ether anesthesia increased the plasma corticosterone levels in rats [7, 27], indicate that the anesthesia itself may induce a stress response. To evaluate corticosterone secretion in response to restraint stress using saliva samples, it could be possible to set a 1-day recovery period from anesthesia, however, 7-day recovery periods would be preferable for using the same individual mice.

When using small experimental animals, such as mice and rats, few studies have examined the evaluation of salivary corticosterone as a stress biomarker, while numerous studies have examined salivary cortisol for stress research in humans $[8,13,26]$. The results of present study may contribute to stress-related research using saliva samples of mice. Saliva collection is a less invasive procedure compared to blood sampling and allows for repeat sampling in the same individual mouse. Moreover, the anesthetic mixture of the three drugs (medetomidine, midazolam and butorphanol) [15] may make it easier for repeated salvia collection. Atipamezole treatment causes mice to rapidly recover from anesthesia. Thus, it is easy to investigate the time course of a response to any stimulus using saliva samples from mice using the same individual.

In the laboratory animal science field, Russell and Burch proposed a practical principle of three Rs (Reduction, Refinement and Replacement) in 1959 [24]. Reduction is defined as obtaining equivalent levels of information from fewer animals in scientific investigation or to obtain maximum information without rise in discomfort level from a small num- ber of animals maintained long term [24]. Refinement is also defined as performing appropriate experimental procedures to improve animal well-being and minimize or avoid discomfort [24]. Our proposal techniques in the present study, using saliva sampling to measure levels of corticosterone in it, would make it possible to compliment Refinement in addition to Reduction practices, since the saliva collection is low invasive technique and is performed under anesthetized condition.

In conclusion, we suggest that salivary corticosterone levels reflect plasma corticosterone levels, and thus, it will be a useful and less-invasive biomarker of physical stress in mice. Moreover, to evaluate restraint stress by the corticosterone level in saliva collected from mice under anesthesia, an adequate recovery period of one week is preferable. The present study may contribute to the concepts of Reduction and Refinement as part of the three Rs, in small animal experiments.

ACKNOWLEDGMENTS. We are grateful to Ms. Akira Koguchi and Mr. Yu Shirakawa for animal care and their helpful assistance in the experiment.

\section{REFERENCES}

1. Borsook, D., George, E., Kussman, B. and Becerra, L. 2010. Anesthesia and perioperative stress: consequences on neural networks and postoperative behaviors. Prog. Neurobiol. 92: 601-612. [Medline] [CrossRef]

2. Colaianna, M., Schiavone, S., Zotti, M., Tucci, P., Morgese, M. G., Bäckdahl, L., Holmdahl, R., Krause, K. H., Cuomo, V. and Trabace, L. 2013. Neuroendocrine profile in a rat model of psychosocial stress: relation to oxidative stress. Antioxid. Redox Signal. 18: 1385-1399. [Medline] [CrossRef]

3. Cotrim, A. P., Sowers, A. L., Lodde, B. M., Vitolo, J. M., Kingman, A., Russo, A., Mitchell, J. B. and Baum, B. J. 2005. Kinetics of tempol for prevention of xerostomia following head and neck irradiation in a mouse model. Clin. Cancer Res. 11: 7564-7568. [Medline] [CrossRef]

4. Derbyshire, D. R. and Smith, G. 1984. Sympathoadrenal responses to anaesthesia and surgery. Br. J. Anaesth. 56: 725-739. [Medline] [CrossRef]

5. Diehl, K. H., Hull, R., Morton, D., Pfister, R., Rabemampianina, Y., Smith, D., Vidal, J. M., van de Vorstenbosch C., European Federation of Pharmaceutical Industries Association and European Centre for the Validation of Alternative Methods 2001. A good practice guide to the administration of substances and removal of blood, including routes and volumes. J. Appl. Toxicol. 21: 15-23. [Medline] [CrossRef]

6. Flecknell, P. 2009. Anesthesia. pp. 19-78 In: Laboratory Animal Anaesthesia 3rd ed, Elsevier, Amsterdam.

7. Gärtner, K., Büttner, D., Döhler, K., Friedel, R., Lindena, J. and Trautschold, I. 1980. Stress response of rats to handling and experimental procedures. Lab. Anim. 14: 267-274. [Medline] [CrossRef]

8. Griebe, M., Nees, F., Gerber, B., Ebert, A., Flor, H., Wolf, O. T., Gass, A., Hennerici, M. G. and Szabo, K. 2015. Stronger pharmacological cortisol suppression and anticipatory cortisol stress response in transient global amnesia. Front. Behav. Neurosci. 9: 63. [Medline] [CrossRef]

9. Harizi, H., Homo-Delarche, F., Amrani, A., Coulaud, J. and 
Mormède, P. 2007. Marked genetic differences in the regulation of blood glucose under immune and restraint stress in mice reveals a wide range of corticosensitivity. J. Neuroimmunol. 189: 59-68. [Medline] [CrossRef]

10. Hellhammer, D. H., Wüst, S. and Kudielka, B. M. 2009. Salivary cortisol as a biomarker in stress research. Psychoneuroendocrinology 34: 163-171. [Medline] [CrossRef]

11. Imamura, T. K., Yoshino, Y., Yamachika, S., Ishii, H., Watanabe, N. Y., Inoue, H. and Nakagawa, Y. 2012. Inhibition of pilocarpine-induced saliva secretion by adrenergic agonists in ICR mice. Clin. Exp. Pharmacol. Physiol. 39: 1038-1043. [Medline] [CrossRef]

12. Japanese Association for Laboratory Animal Science 1987. Guidelines for animal experimentation. Exp. Anim. 36: 285-288 (in Japanese).

13. Jones, A., McMillan, M. R., Jones, R. W., Kowalik, G. T., Steeden, J. A., Deanfield, J. E., Pruessner, J. C., Taylor, A. M. and Muthurangu, V. 2012. Adiposity is associated with blunted cardiovascular, neuroendocrine and cognitive responses to acute mental stress. PLoS ONE 7: e39143. [Medline] [CrossRef]

14. Kanesaka, T., Taya, K. and Sasamoto, S. 1992. Radioimmunoassay of corticosterone using ${ }^{125}$ I-labeled radioligand. J. Reprod. Dev. 38: j85-j89 (in Japanese with English abstract). [CrossRef]

15. Kawai, S., Takagi, Y., Kaneko, S. and Kurosawa, T. 2011. Effect of three types of mixed anesthetic agents alternate to ketamine in mice. Exp. Anim. 60: 481-487. [Medline] [CrossRef]

16. Kirschbaum, C. and Hellhammer, D. H. 1989. Salivary cortisol in psychobiological research: an overview. Neuropsychobiology 22: 150-169. [Medline] [CrossRef]

17. Ma, X. M. and Lightman, S. L. 1998. The arginine vasopressin and corticotrophin-releasing hormone gene transcription responses to varied frequencies of repeated stress in rats. $J$. Physiol. 510: 605-614. [Medline] [CrossRef]

18. Matta, S. G., Beyer, H. S., McAllen, K. M. and Sharp, B. M. 1987. Nicotine elevates rat plasma ACTH by a central mechanism. J. Pharmacol. Exp. Ther. 243: 217-226. [Medline]

19. Mormède, P., Andanson, S., Aupérin, B., Beerda, B., Guémené, D., Malmkvist, J., Manteca, X., Manteuffel, G., Prunet, P., van Reenen, C. G., Richard, S. and Veissier, I. 2007. Exploration of the hypothalamic-pituitary-adrenal function as a tool to evaluate animal welfare. Physiol. Behav. 92: 317-339. [Medline] [CrossRef]
20. Naganuma, Y., Morii, K., Saitou, T., Hashimoto, M. and Koyama, H. 2013. Effect of Medetomidine/Midazolam/Butorphanpl in three mouse strains. Exp. Anim. 62: Suppliment, S86.

21. Obayashi, K. 2013. Salivary mental stress proteins. Clin. Chim. Acta 425: 196-201. [Medline] [CrossRef]

22. Rademacher, D. J., Meier, S. E., Shi, L., Ho, W. S., Jarrahian, A. and Hillard, C. J. 2008. Effects of acute and repeated restraint stress on endocannabinoid content in the amygdala, ventral striatum, and medial prefrontal cortex in mice. Neuropharmacology 54: 108-116. [Medline] [CrossRef]

23. Rasmussen, D. D. 1998. Effects of chronic nicotine treatment and withdrawal on hypothalamic proopiomelanocortin gene expression and neuroendocrine regulation. Psychoneuroendocrinology 23: 245-259. [Medline] [CrossRef]

24. Russell, W. M. S. and Burch, R. L. 1969. The Principles of Humane Experimental Technique, Universities Federation for Animal Welfare, Hertfordshire (reprinted in 1992).

25. Taylor, R., Hayes, K. E. and Toth, L. A. 2000. Evaluation of an anesthetic regimen for retroorbital blood collection from mice. Contemp. Top. Lab. Anim. Sci. 39: 14-17. [Medline]

26. Therrien, F., Drapeau, V., Lalonde, J., Lupien, S. J., Beaulieu, S., Doré, J., Tremblay, A. and Richard, D. 2010. Cortisol response to the Trier Social Stress Test in obese and reduced obese individuals. Biol. Psychol. 84: 325-329. [Medline] [CrossRef]

27. Tohei, A., Tomabechi, T., Mamada, M., Akai, M., Watanabe, G. and Taya, K. 1997. Effects of repeated ether stress on the hypothalamic-pituitary-testes axis in adult rats with special reference to inhibin secretion. J. Vet. Med. Sci. 59: 329-334. [Medline] [CrossRef]

28. Tohei, A., Mogi, Y., Kon, H., Hokao, R. and Shinoda, M. 2003. Strain difference in pituitary-adrenal axis between Wistar-Imamichi and Long Evans adult male rats. Exp. Anim. 52: 437-439. [Medline] [CrossRef]

29. Tohei, A., Umezu, M., Kanai, T., Yamaguchi, K., Kosaku, A., Kon, H. and Shinoda, M. 2010. Pituitary-adrenal functions in a hereditary hypothyroid (rdw) rat. Exp. Anim. 59: 95-98. [Medline] [CrossRef]

30. Yamada, S., Maruyama, S., Takagi, Y., Uchida, S. and Oki, T. 2006. In vivo demonstration of $\mathrm{M}_{3}$ muscarinic receptor subtype selectivity of darifenacin in mice. Life Sci. 80: 127-132. [Medline] [CrossRef] 